\title{
Menata Domain Psikologis Pasca Bencana
}

\author{
Muhammad Idrus
}

A member of International aid from Tiongkok Wu Min recently has finished the task at disaster region of tsunami and returned to the mother land. The press has chance to interview Wu Min. Wu Min is still look tired, always feel tired body, can not sleep, decrease willing to eat so that his bodyweight is decrease drastically. Although Wu Min has come back to home, but still shadow in Wu Min's memory the situation of disaster at the field where tsunami happened, instead, it si difficult to lose from mind. Wu Min told that he undergoes many accidents in conducting aid activities to the victims at the field, and Wu Min sees by eyes the situation of disaster above-mentioned. Because of heart and feeling shockdown and work so hard at that region, Wu Min is look like rather depression (Radio of China broadcasting in Indonesia).

Kata kunci: bencana, trauma dan penanganan

A nggota tim bantuan internasional Tiongkok Wu Min baru-baru ini menyelesaikan tugasnya di daerah bencana tsunami dan kembali ke tanah air. Wartawan sempat mewawancarainya. Wu Min masih kelihatan sangat letih, selalu merasa badan lemas, tidak dapat tidur pulas, nafsu makannya berkurang sehingga berat badannya menurun banyak. Walaupun telah kembali ke rumahnya, tapi masih terbayangbayang di benaknya keadaan malapetaka daerah bencana tsunami, bahkan sulit dihapuskan dari ingatannya. Wu Min mengatakan, ia mengalami banyak kejadian dalam melakukan kegiatan bantuan kepada korban di daerah bencana, dan juga menyaksikan dengan mata kepalanya sendiri keadaan malapetaka tersebut. Karena hati dan perasaan terpukul keras serta bekerja berat di daerah bencana, Wu
Min kelihatan agak depresi (Siaran Radio Cina dalam bahasa Indonesia).

Wu Min adalah salah seorang relawan yang berangkat ke Aceh, yang secara langsung merasakan suasana duka yang melanda daerah bencana gempa dan tsunami yang terjadi 26 Desember 2004 yang lalu. Potret yang dibawa Wu Min memang tidaklah sama dengan apa yang dapat direkam relawan lainnya yang berasal dari negara lain atau yang berasal dari Indonesia sendiri. Namun yang pasti ada kesamaan cerita yang dibawa, yaitu cerita tentang kehilangan entah itu orang yang dicintai, harta benda, cerita tentang fenomena hancumya sarana dan prasarana kota, serta kerusakan fisik lainnya.

Peristiwa kehilangan orang yang dicintai menjadi salah satu tema utama tragedi tersebut. Sebut saja penuturan salah seorang rekan di Pusat Studi Islam (PSI) UII yang kehilangan sebanyak 54 orang 
keluarganya yang hingga hari ini tidak diketahui keberadaannya dan dapat dipastikan mereka termasuk yang tewas dalam tragedi tersebut. Dr. Husni, seorang dosen dari Fakultas Pertanian Universitas Syiah Kuala kehilangan sebanyak 88 orang anggota keluarganya.

Bukan hanya mereka yang secara langsung mengalami bencana saja yang merasakan dampak bencana, peristiwa kehilangan orang yang dicintai juga melanda para sukarelawan. Muncul perasaan ketidakberdayaan (hopeless) saat menyaksikan banyaknya mayat bergelim-pangan, serta perasaan bersalah saat tidak lagi mampu untuk menyelamatkan orang-orang yang seharusnya diselamatkannya. Pada ujung-ujungnya rasa bersalah dan kehilangan ini memunculkan banyak gangguan psikologis seperti stress, kehilangan orientasi, hopeless, frustasi, hingga yang terburuk adalah depresi dan gangguan kejiwaan.

\section{Dampak Psikologis Bencana}

Pada tanggal 26 Desember 2004 terjadi gempa tektonik yang diikuti gelombang tsunami dengan dahsyat menggoncangkan Aceh dan sebagian Sumatera Utara'. Puluhan ribu nyawa melayang ${ }^{2}$, rumahrumah hancur, prasarana dan sarana berantakan. Jerit tangis dan ratapan pilu mengoyak nurani. Bukan hanya masyarakat setempat yang menangis meratapi bencana itu, namun seluruh bangsa Indonesia meratap dan menangis, tenggelam dalam duka yang dalam. Sungguh suatu tragedi yang sangat luar biasa ${ }^{3}$.

Tidak berbilang minggu, beberapa hari setelah terjadinya bencana tersebut, stasiun-stasiun televisi berulangkali menayangkan rekaman video amatir yang kebetulan merekam peristiwa tersebut.
Tayangan ketegangan dan kekejaman gelombang tsunami yang dialami masyarakat Aceh dan sekitarnya serasa memaku seluruh urat sendi masyarakat. Visualisasi peristiwa yang tak sengaja terekam dipenuhi dengan adegan yang diliputi dengan rasa cemas, panik, gelisah, takut, tangisan, khawatir dan kesedihan. Pada akhimya, akumulasi dari emosi negatif yang telah terekam tersebut menstimulasi suatu asosiasi psikologis pada pikiran or

1 Ketika musibah terjadi pada Minggu (26/ 12/2004) pagi, masyarakat Aceh di Jakarta sedang dalam suasana halal bi halal dengan Wakil Presiden Jusuf Kalla. Suasana halal bi halal yang diiringi lagu-lagu dan tarian daerah Aceh tak mampu membangkitkan suasana yang nostalgia. Pengunjung dan undangan tergesa-gesa keluar Istora dan mencoba menghubungi kerabatnya dj Nanggroe Aceh Darussalam (NAD), tetapi tidak satu pun berhasil melakukan kontak. Apa nyana, semua buru-buru meninggalkan Istora.

2 Harian Kedaulatan Rakyat (2/2/2005) mencatat sedikitnya 127.749 dinyatakan hilang sedangkan korban meninggal dunia sebanyak 109.169 orang. Jumlah pengungsi tercatat sebanyak 426.849 orang yang ditampung di 66 lokasi di 18 kabupaten/kota di NAD dan Sumut. Jumlah korban meninggal total yang banyak dengan kerusakan bangunan maupun lingkungan hidup yang cukup berat akibat terjangan gelombang tsunami di Aceh dan Sumatera Utara, 26 Desember 2004 jauh lebih besar dibanding tragedi World Trade Center, 11 September 2001 yang menewaskan sekitar 3.500 manusia. Bahkan sebagian kalangan mengakui bahwa akibat destruktif Perang Dunia II masih kalah hebat daripada dampak tsunami yang terjadi di Aceh dan Sumut.

${ }^{3}$ Pakar Seismologi Teknik dan Tsunami BMG, Fauzi MSc. Phd menyatakan, untuk ukuran Indonesia, gempa bumi dengan skala 8,9 skala ritcher (SR) yang disusul badai Tsunami yang menghantam Aceh dan kawasan lainnya di Utara P. Sumatera kemarin merupakan bencana terbesar dalam 100 tahun terakhir. 
ang yang menontonnya. Suatu asosiasi antara pikiran takut, takjub dan duka hingga kemudian memungkinkan terbentuknya gejala-gejala trauma.

Setelah tayangan tersebut, ternyata efek distorsi yang ditimbulkannya sungguh luar biasa. Masyarakat mengalami 'trauma tsunami" yang berlebihan dan cenderung tidak rasional. Di Yogyakarta, masyarakat seperti dikomando untuk memasak sayur lodeh yang berisi 12 macam sayuran. Menurut isu, memasak sayur lodeh adalah "dawuh" sultan sebagai upaya tolak "tsunami". Ternyata histeria tsunami bukan hanya terjadi di Yogyakarta saja, beberapa kota pantai ${ }^{4}$ juga mengalami situasi yang sama. Masyarakat dicekam rasa ketakutan akan bahaya datangnya gempa susulan dan datangnya gelombang tsunami. Meski untuk yang terakhir ini terkadang sudah dijamin oleh Badan Meteorologi dan Geofisika (BMG) mengenai ketidakbenaran isu akan adanya gempa bumi dan gelombang tsunami di daerah mereka.

Informasi tersebut serasa tidak memiliki kekuatan untuk melawan kecemasan yang melanda warga masyarakat. Kecemasan yang terlanjur menjadi sebuah efek traumatik bencana, begitu mendominasi alam pikir masyarakat saat ini. Analis dan paparan tentang segala hal ihwal gempa dan tsunami dengan segala kemungkinan ke depan dari berbagai instansi terkait dan berwenang cenderung tidak disimak dengan baik, terutama karena kecemasan dan kepanikan. Alhasil masyarakat mudah digerakkan untuk melakukan aktivitas tertentu dengan dasar tsunami sebagai rujukannya.

Perasaan panik, takut dan yang sejenisnya juga merambah pada seluruh komponen masyarakat tanpa membedakan jenis kelamin ataupun ras. Simak saja keluhan seorang ibu tentang anaknya dalam rubrik konsultasi psikologi di harian Pikiran Rakyat (5/1/2005, http://www.pikiranrakyat.com/cetak/2005/0105/09/hikmah/ konsultasi.htm ) berikut ini:

Saya adalah seorang ibu rumah tangga yang mempunyai 2 orang anak perempuan masing-masing berusia 10 tahun dan 4 tahun. Sejak peristiwa badai tsunami di Aceh dan Sumatra Utara pada tanggal 26 Desember 2004 yang lalu, kami sekeluarga sering menyaksikan berita tersebut yang ditayangkan di televisi. Beberapa hari ini, saya melihat adanya perubahan tingkah laku pada anak saya yang kecil. Tampaknya dia sering merasa takut terutama ketika hujan turun, anak saya selalu mendekati saya dan bersembunyi di tubuh saya seakan-akan tidak mau melihat dunia sekitarnya dan tidak mau melepaskan diri dari saya. Setiap kali saya hendak pergi dari rümah, dia menjadi rewel dan tidak mau ditinggalkan sendirian padahal sebelumnya dia mau ditinggal dengan pengasuhnya di rumah. Selain itu, beberapa hari ini tidumya juga sering terganggu seperti sedang mengalami mimpi yang buruk.

Dapat dibayangkan jika hanya menyaksikan tayangan televisi bencana saja masyarakat banyak yang mengalami efek traumatik. Lantas, bagaimana dengan

${ }^{4}$ Banyak nelayan yang tidak berani melaut karena muncul kekhawatiran akan datangnya gelombang tsunami. Padahal jelas-jelas pihak BMG telah memberikan informasi bahwa daerah mereka bukan termasuk daerah yang dilewati tsunami. Beberapa minggu lalu ratusan orang di Kota Bau-Bau, Kabupaten Buton, Sulawesi Tenggara dan ribuan orang di Palu lari tunggang langgang ke luar rumah menuju tempat-tempat tertinggi di Palu, beberapa saat setelah terjadi gempa. Hal yang sama beriaku di Thailand, Malaysia, dan India, sambil berteriak-teriak histeris mereka berhambur dengan memanggul harta bendanya menuju gunung atau bukit terdekat 
mereka yang menyaksikan atau bahkan mengalami peristiwa tersebut. Dari catatan yang dibuat Himpsi (organisasi profesi psikolog dan ilmuwan psikologi) ternyata saat ini tercatat 500.000 rakyat Aceh mengalami trauma psikologis, dan 100.000 di antaranya mengalami trauma yang cukup parah 5 .

Penggalan laporan yang dibuat oleh Wu Min (relawan Cina) berikut ini setidaknya dapat menggambarkan bagaimana kondisi mereka yang mengalami peristiwa tersebut.

Wu Min dalam kenangannya mengatakan, begitu tiba di daerah bencana, karena di lapangan bencana masih belum dibersihkan, tampak banyak jenazah bergelimpangan di mana-mana dan mulai membusuk, yang paling mengenaskan ialah jenazah anak-anak. Personel yang membersihkan jenazah-jenazah pasti memikul tekanan psikologis yang besar, banyak jenazah bengkak karena terendam air laut, dan segera terkoyak begitu diangkat. Ada suatu hal yang menggebrak hati Wu Min, pada hari pertama mengadakan inspeksi ke rumah sakit, dia melihat seorang berpakaian putih duduk di atas bangku di tengah-tengah jalan dengan tidak menghiraukan hilir mudiknya kendaraan di pinggirnya. Ekspresi wajah orang itu hilang, mata kuyu tak berseri, bahkan tidak berkejap sedikitpun terhadap mobil yang berlaju cepat di sisinya. Reruntuhan yang direndam air laut di sekitarnya adalah rumahnya, dan dia adalah satu-satunya orang yang selamat di antara semua anggota keluarganya. Dia beruntung, karena masih hidup, tapi ia sangat malang karena mentalnya diluluh-lantakan oleh malapetaka tsunami (Siaran Radio Cina dalam bahasa Indonesia).

Tak terbayangkan, trauma hebat para korban yang mengalami langsung bencana nasional terbesar sepanjang sejarah dalam satu abad ini. Terlebih bagi mereka yang telah kehilangan saudara atau anggota keluarganya. Dapat dipastikan betapa dalamnya efek trauma temadap ratusan ribu korban gelombang tsunami di Aceh dan Sumut, yang juga dialami sebagian penduduk Malaysia, India, Sri Langka, Thailand, Maladewa, dan lain-lainnya.

Lalu apa dampak trauma tersebut dalam kehidupan keseharian mereka? lbrahim (2005) dalam tulisannya menyatakan bahwa mereka yang mengalami peristiwa tersebut akan mengalami stres berkepanjangan dan berusaha untuk tidak mengalami stres yang sedemikian itu. Dalam menjalani hidup keseharian mereka bereaksi terhadap pengalaman traumatik dengan gejala ketakutan, keputus-asaan, ketidakberdayaan, kerap terbayang kembali peristiwa traumatik, sampai perilaku menghindar dari ingatan traumatik.

Perilaku menghindar dari ingatan traumatik memang sangatlah irrasional, namun bagi mereka yang mengalami peristiwa tersebut, situasi tersebut memang harus dihindari. Lazimnya para korban bencana alam, akan menghindari segala sesuatu yang disangka akan membawa kembali pada ingatan peristiwa traumatik itu ke dalam relung jiwanya. Penuturan seorang rekan di PSI UII yang keluarganya terkena langsung peristiwa tersebut menemukan ada korban yang menjerit-jerit tatkala melihat genangan air yang ada di kolam kamar mandi ${ }^{6}$. Bagi para korban yang dilihatnya

5 Suara Karya, (11/01/2005) memberitakan bahwa sekitar 300.000 pengungsi koban tsunami dari Aceh dan Sumut berpotensi sakit jiwa akibat depresi yang sangat berat karena kehilangan istri, anak, suami, saudara, famili dan harta benda.

${ }^{6}$ Penuturan Aminah, warga Lamnga yang mengungsi, Lisna, anaknya yang berumur 1,5 tahun, hanya mau minum air putih. "la sama 
bukanlah sekadar air yang ada dalam bak mandi, tetapi baginya mungkin memunculkan bayangan peristiwa tatkala gelombang tsunami yang tingginya melebihi rumahnya mendatanginya dan melontarkannya ke atas pepohonan.

Pengalaman traumatik ini tidak akan berhenti hanya sebatas itu saja, dapat juga terbawa dalam perilaku sehari-hari yang berusaha melupakan peristiwa tersebut dengan bekerja keras dengan tanpa memperhatikan kondisinya, atau bahkan terbawa-bawa dalam mimpi-mimpi dan pembicaraan sehari-hari. Ini adalah salah satu cara coping untuk mengatasi situasi stres yang melanda mereka.

Dalam wawancaranya Wu Min ${ }^{7}$ (Siaran Radio Cina dalam bahasa Indonesia) pernah menemui seorang petani yang sekuat tenaga membantu pekerjaan tim. Sebelum terjadinya malapetaka tsunami, seluruh anggota keluarganya berjumlah 54 orang, tapi sekarang hanya tinggal dia sebatang kara. Dikatakannya, begitu matanya melek, dia harus terus bekerja keras, kalau tidak, akan terbayang terus wajah anggota keluarganya satu persatu. Dia tidak dapat menanggung kepedihan itu, hanya dengan bekerja berat tak henti-hentinya baru dapat menyelamatkan dirinya dari gangguan psikologis.

Mereka yang mengalami situasi tersebut menjadi terlalu peka terhadap kondisi sekitar. Bukan hanya itu, kadang terjadi penumpulan berpikir, kesulitan untuk mengingat dan merasa tersisih dari lingkungannya. Situasi kecil dan sederhana dapat menjadi pemicu kepanikan yang berlebihan yang dapat menjurus ke arah depresi yang akut. Jika hal tersebut dibiarkan, maka akan terjadi gelombang pasca tsunami berupa banyaknya masyarakat yang terganggu kejiwaannya.

\section{Intervensi Psikologis Pasca Bencana.}

Dipahami bahwa trauma bukan hanya sebagai gejala psikhis yang bersifat individual. Trauma muncul sebagai akibat dari saling keterkaitan antara ingatan sosial dan ingatan individual tentang peristiwa yang mereka alami dan mengguncangkan jiwa mereka. Setiap kondisi trauma yang dialami individu dapat mencetuskan satu gangguan psikologis. Apabila gangguan tersebut terjadi dalam waktu sebelum 1 bulan disebut dengan gangguan stres akut, sedangkan gangguan yang terjadi sesudah 1 bulan disebut dengan gangguan stres pasca trauma.

Gangguan stres akut dapat berwujud kecemasan, depresi, bahkan gangguan jiwa yang berat (psikotik). Sementara perwujudan gangguan psikologis pada gangguan stres pascatrauma (GSPT, gangguan sindroma pasca-traumatik atau PTSD, posttraumatic syndrome disorder) seringkali dimanifestasikan dengan gejala kecemasan, depresi, tingkah laku impussif, dan imatable (mudah marah dan tersinggung), adanya hambatan daya ingat, sulit berkonsentrasi, emosi yang labil, sakit kepala, dan vertigo. Kondisi tersebut dapat ringan tetapi dapat

sekali tidak mau makan, dari hari ke hari semakin kurus," kata perempuan berusia 35 tahun itu. Sementara itu, anaknya yang lain, Amelia, 3,5 tahun, mengalami trauma dan dibayangi ketakutan. "la suka menangis dan tidak mau kembali ke rumah, takut air," kata Aminah (Tempo Interaktif, Minggu, 09 Januari 2005 | 11:20 WIB)..

7 Wu Min juga mengakui bahwa dirinya dan juga para anggota tim bantuan internasional Tiongkok juga tidak sedikit mengalami trauma dengan kejadian tersebut, manifestasinya mereka bercerita tak habishabisnya atau bungkam dengan seribu bahasa. 
pula memengaruhi seluruh aspek kehidupan sehingga mengganggu kegiatan sehari-hari.

Dalam Diagnostic and Statical Manual of Menthal Disorders (DSM) III dan IV serta Pedoman Penggolongan dan Diagnosis Gangguan Jiwa (PPDGJ) III di Indonesia dinyatakan bahwa gejala yang ditemukan pada mereka itu menggambarkan suatu stres yang terjadi berbulan-bulan, bahkan bertahun-tahun. Ibrahim (2005) menyebutkan bahwa gangguan stres pascatrauma dapat berlangsung sampai dengan jangka waktu 30 tahun.

Perilaku yang ditampilkan individu, salah satunya muncul dalam sikap berusaha menghindar secara persisten terhadap kejadian yang mirip tanpa alasan yang jelas. Mereka selalu dibayang-bayangi mimpi tentang peristiwa yang menakutkan dan terjadi secara berulang-ulang, sehingga mereka mengalami gangguan di saat tidurnya. Bukan hanya itu, individu yang mengalami situasi tersebut tatkala terjaga juga kerap merasakan seolah-olah kejadian traumatis itu kembali terjadi di hadapannya. Muncul halusinasi dan mereka begitu peka terhadap lingkungannya secara berlebihan (cenderung curiga, paranoid), serta kewaspadaan berlebihan.

Secara sederhana GSPT adalah suatu kondisi kejiwaan yang menimbulkan suatu "gejala khas" akibat suatu peristiwa trauma psikologis yang berada di luar batas kemampuan daya tahan manusia yang ditandai dengan (1) adanya penghayatan kembali peristiwa traumatis tersebut (re-experiencing); (2) adanya penghindaran terhadap peristiwa traumatis tersebut (avoidance and numbing), (3) adanya kesadaran atau kewaspadaan yang berlebihan (hyperarousal).

Gejala-gejala yang terjadi yang dirasakan anak dan orang dewasa memang tidak selalu memperlihatkan gejala yang sama $^{8}$. Namun secara umum ketiga karakteristik di atas kerap muncul pada penderita GPST. Dapat dibayangkan situasi yang saat ini dihadapi para korban bencana alam, di luar rasa kehilangan dari orangtua, kakak, adik, saudara, anak dan orang-orang yang dicintai lainnya ataupun kehilangan harta benda lainnya. Mereka juga mengalami situasi yang akan menghantui mereka selama sisa perjalanan hidupnya.

Dengan begitu langkah penataan dalam membangun Aceh dan sebagian Sumatera Utara yang mengalami bencana gempa dan tsunami haruslah terlebih dahulu memahami kondisi individual korban bencana alam tersebut. Beberapa karakteristik sebagai bawaan mereka yang mengalami stres hendaklah dipahami dengan benar oleh para relawan ataupun pemerintah daerah yang menginginkan adanya relokasi.

Mengingat sisi penderitaan yang dialami korban bencana alam ini serta kondisi individual yang jelas-jelas berbeda, maka tampaknya pendekatan individual menjadi solusi yang terbaik dalam proses penanganan korban bencana alam. Hanya saja menjadi persoalan ketika jumlah individu yang harus ditangani oleh relawan begitu banyak. Pada sisi ini muncul dilematis antara keinginan untuk membantus sesama namun terhalang situasi keterbatasan yang dimiliki.

Dipahami bahwa situasi traumatik yang dialami korban bencana alam tidak terjadi

${ }^{8}$ Mereka tidak menyadari telah mengidap stres pasca-trauma karena gejalanya disimpulkan sebagai penyakit biasa, seperti tidak ada nafsu makan, sering sakit kepala, perut kembung, dan sesak napas. Kalau yang dewasa saja tidak menyadari trauma yang diderita, bagaimana dengan anak-anak ? 
dengan sendirinya. Analisis Sheridan dan Radmacher (1992) dan McDaniel (1995) menyatakan bahwa faktor-faktor biologis dan sosial mempengaruhi fungsi biologis dan memainkan peranan penting bagi kesehatan dan keadaan sakit.

Dalam hal ini Partosuwido (2000) menyatakan bahwa tinjauan proses psikososial dibidang kesehatan dapat dilihat dari dua pandangan, yaitu pandangan perilaku dan pandangan psikodinamik. Pandangan perilaku melihat sakit (illness). sebagai perilaku yang dikendalikan oleh prinsip-prinsip psikologik. Pandangan kedua adalah dari segi psikodinamika yang bermuara pada teori Freud, teori psikoanalisis, yang mengajarkan bahwa perilaku seseorang dikendalikan oleh bagian sadarnya. Dengan begitu, kondisi sakit secara fisik dapat dicari penyebabnya dari konflik-konflik batin yang kemudian disalurkan melalui kondisi fisik.

Merujuk pada teori ini, tampaknya model pendekatan yang dapat dilakukan dalam terapi pasca bencana korban gempa dan tsunami adalah modifikasi perilaku dan membangkitkan kesadaran para korban. Senada dengan hal ini adalah apa yang dikemukakan oleh Purnomo (2005) yang mengajukan model penanganan psikologis pasca bencana para korban tersebut dengan pola psikoterapi.

Selanjutnya pada jangka menengah, rehabilitasi psikis para korban sebaiknya dilakukan dengan menggunakan strategi kelompok. Dengan dipandu para fasilitator, para korban dengan gangguan ringan secara berkelompok dilatih untuk memakna ulang seluruh peristiwa, membangkitkan semangat hidup baru, meningkatkan harga diri dan motivasi baru serta saling memberikan dukungan. Pada jangka panjang, langkah yang harus ditempuh adalah memperkuat ketahanan diri para korban agar di masa mendatang mereka mampu menghadapi setiap masalah - apa pun persoalannya 一, sambil beradaptasi dengan tantangan baru.

Lazimnya bahwa terjadi proses interaksi antara individu dengan lingkungannya, maka sebenarnya persoalan penanganan korban bencana ini juga harus dapat melihat interkasi antara individu dengan lingkungan sebagaimana diungkap Caplan dan Nelson (1973) yang melihatnya sebagai proses timbal balik. Dengan begitu, harus disadari bahwa penanganan yang hanya melihat satu sisi saja kurang dapat membantu peyembuhan penyakit mental yang diderita penderita.

Teori yang diajukan Caplan dan Nelson (1973) merupakan pandangan yang dapat mengubah pandangan terdahulu sebagaimana dilansir para ahli psikoanalisis. Pandangan lebih baru ini menyatakan bahwa penyebab gangguan kesehatan mental tidak hanya keadaan intra-psikis saja, tetapi juga mungkin disebabkan lingkungan atau interaksi individu dengan lingkungannya. Dengan begitu, dalam penanganan korban bencana alam ini perlu melakukan sebuah pendekatan psikologi baru.

Jika selama ini pendekatan yang banyak dilakukan dengan menggunakan teori psikodinamika ataupun psikoanalisis, yang lebih banyak menekankan pada teori perubahan perilaku dan kejadian masa lalu individu tanpa campur tangan komunitas sosialnya, maka saat ini dibutuhkan pendekatan yang lebih dapat menjelaskan fenomena sakitnya individu dan melihat konteks komunitasnya.

Pada sisi tersebut tampaknya perlu menerapkan konsep psikologi komunitas dalam penanganan korban trauma pasca bencana. Secara ringkas psikologi komu- 
nitas merupakan aplikasi prinsip-prinsip ilmu tingkah laku untuk mengerti dan memecahkan bermacam-macam problema dan situasi komunitas, tidak hanya problem kesehatan mental (Heller dan Monahan, 1977).

Partosuwido (2000) menyatakan bahwa dalam bidang kesehatan mental, fokus psikologi komunitas terutama adalah pada preverensi atau menghindari terjadinya defisit. Lebih jauh dikemukakan Partosuwido (2000) bahwa tujuan preverensi ini adalah mengurangi resiko gangguan emosi di antara para anggota komunitas atau masyarakat, usaha pengurangan risiko gangguan emosi tidak hanya ditujukan pada individu-individu tertentu, melainkan ditujukan pada populasi.

Dengan begitu, sebenarnya penanganan GSPT para korban tidak dapat dilaksanakan dengan tanpa menyertakan komunitasnya. Artinya, tidak mungkin untuk menyembuhkan penyakit mental yang dirasakan para korban saat ini, hanya dengan memberi terapi pada yang bersangkutan tanpa juga menyertakan lingkungan tempat dimana individu itu berada $^{9}$, inilah pendekatan public health (kesehatan masyarakat) yang digunakan psikologi komunitas.

Penggunaan pendekatan kesehatan masyarakat merupakan pendekatan terbaru dalam proses penanganan gangguan emosi individu. Pendekatan sebelumnya dikenal dengan pendekatan yang lebih manusiawi, yaitu memperlakukan penderita secara manusiawi. Pendekatan kedua dilakukan oleh Freud yang memberi perhatian pada kehidupan intra-psikis manusia.

Dalam pendekatan kesehatan masyarakat ini dikenal tiga macam prevensi ${ }^{10}$, yaitu:
1. Prevensi primer, yang bertujuan untuk mengurangi kemungkinan terkenanya penyakit pada rakyat, caranya dengan vaksinasi;

2. Prevensi sekunder, yang merupakan usaha untuk mengurangi lamanyua penyakit bagi mereka yang telah menderita. Fokusnya adalah menemukan penyakit sedini mungkin, dan memberikan penyembuhan seawal mungkin;

3. Prevensi tersier, yaitu usaha untuk mengurangi akibat penyakit bagi mereka yang sudah menderita, misalnya dengan rehabilitasi (Kaplan, dkk., 1993)

Hanya saja tampaknya tidak mudah untuk melakukan prevensi bagi gangguan kesehatan mental dibanding dengan penyakit fisik lainnya. Roan (1984) mengajukan tiga tipe program pelaksanaan prevensi, yaitu (1) program untuk seluruh komunitas (community-wide), (2) program milestone, dan (3) program risiko tinggi (high risk program).

Dalam konteks bencana alam NAD dan Sumatera Utara ini, program yang dimaksud masuk dalam kelompok program risiko tinggi. Dalam konteks ini program prevensi dapat berupa intervensi krisis (Altrocchi, 1980; Caplan, 1964, Korchin, 1976;

${ }^{9}$ Kerap terjadi selesainya pemberian dan individu yang sakit dinyatakan sehat, tetapi komunitasnya tidak mendukung menyebabkan individu tersebut kambuh kembali penyakitnya. Situasi ini sebenarnya tidaklah menguntungkan bagi sebuah terapi penyembuhan, sebab individu tersebut akan tetap dinyatakan sakit oleh lingkungannya. Padahal secara klinis, dia telah dinyatakan sembuh.

10 Prevensi adalah usaha untuk melakukan pencegahain agar seseorang tidak terkena sakit 
Rappaport, 1977). Perlu dipahami bahwa krisis bukanlah sakit jiwa, namun yang dimaksud krisis adalah keadaan yang sangat menekan dan sangat berkesan, sehingga dapat menjadi sumber gangguan mental.

Korchin (1976) mengemukakan dua macam krisis, yaitu krisis aksidental dan krisis perkembangan. Krisis aksidental adalah keadaan yang kurang dapat diramalkan sebelumnya atau yang tidak dapat diramalkan, sehingga tidak dapat dihindari. Termasuk dalam krisis ini misalnya kematian orang yang dicintai karena gempa, bencana. Krisis perkembangan adalah krisis yang terjadi dalam perkembangan menuju masa kemasakan (maturasi). Untuk mereka yang mengalami bencana, maka dapat dimasukkan dalam kelompok krisis aksidental.

Orang yang dalam keadaan krisis akan mengalami kecemasan yang tinggi, ia membutuhkan cara-cara bagaimana menghadapi keadaan tidak nyaman yang sedang dideritanya. Untuk itu, perlu dilakukan intervensi krisis dengan tujuan: (a) mengurangi ketegangan, kecemasan, kebingungan dan ketidak berdayaan; (b) mengembalikan orang yang dalam krisis ke fungsi sebelumnya; dan (c) membantu orang yang bersangkutan, keluarganya, dan orang-orang lain yang penting bagi penderita (Korchin, 1976).

Menyadari bahwa sulit rasanya berharap kesembuhan dari masalah stres pasca tragedi para korban bencana alam gempa dan tsunami jika hanya dengan mengandalkan terapi individual semata, maka rasanya perlu dibantu dengan mengkondisikan dukungan sosial kepada mereka. Block (2005) menyatakan bahwa dukungan sosial dapat secara cepat menurunkan dampak stres. Pendekatan psikologi komunitas yang tidak hanya menekankan pada sisi individu yang sedang mengalami stres saja memungkinkan untuk mempercepat proses penyembuhan korban bencana alam ini.

Artinya gangguan kejiwaan pascatrauma yang dialami oleh para korban gempa dan tsunami itu harus secepatnya ditangani yang melibatkan tidak hanya kelompok tertentu saja (psikater atau psikolog saja) tetapi juga oleh banyak kalangan. Kolaborasi dan koordinasi antara semua elemen terkait (tokoh masyärakat, lembaga swadaya masyarakat = LSM, pemuka agama, pemerintah, swasta, universitas, dan lain-lain) harus dilakukan secara sinergis, komprehensif dan profesional agar mencapai hasil optimal.

Dengan melakukan sinergi, penanganan tugas-tugas kemanusiaan di daerah bencana akan lebih efektif dan efisien, sehingga akan lebih mudah mencapai hasil yang optimal. Tentunya mereka perlu dukungan fasilitas dan kenyamanan dalam bekerja. Untuk itu segala bantuan sosialkemanusiaan yang mengalir ke Aceh dan Sumut sebagian harus dimanfaatkan guna mendukung kinerja para profesional dan relawan di wilayah yang serba darurat karena rawan gangguan keamanan maupun ancaman penyakit, belum lagi ketidakmampuan dalam pengelolaan dana bantuan.

Terkait dengan menejemen dana bantuan Presiden Susilo Bambang Yudhoyono seusai KTT Tsunami di depan pers menyatakan, bahwa serupiahpun dana bantuan untuk Aceh tidak akan diselewengkan. Artinya, dana-dana yang diberikan lewat Pemerintah, benar-benar digunakan dan disalurkan bagi masyarakat yang benar-benar membutuhkan serta digunakan untuk rehabilitasi dan rekonstruksi berbagai sarana dan prasarana. 
- Pertanyaannya, bagaimanakah cara efektif untuk memantau dan mengawasi banjir uang ini agar tidak diselewengkan (Muhammad, 2005).

Serasa sulit untuk mendapatkan jaminan bahwa dana-dana bantuan tersebut tidak bocor di tengah jalan. Keraguan Muhammad (2005) tampaknya tidak dapat dinafikan. Sebab meski penggunaan danadana ini akan diaudit, baik oleh aparat Pemerintah dan dapat juga dilakukan oleh auditor independent namun tidak menjamin bahwa tidak ada dana yang diselewengkan. Muhammad (2005) menyatakan bahwa auditor lazimnya melakukan pemeriksaan berdasarkan bukti-bukti pengeluaran uang, selama bukti-bukti itu sah, maka auditor tidak akan banyak cincong, dan tidak sulit untuk memark-up harga-harga meskipun diikuti dengan bukti-bukti yang sah. Tidak tertutup pula kemungkinan adanya pemborosan penggunaan dana-dana itu, misalnya untuk rapat-rapat yang sebenamya cukup dilangsungkan di kantor-kantor, oleh aparat Pemerintah diselenggarakan di hotel-hotel mewah, jadi sekaligus dijadikan ajang piknik.

Pada akhirnya, hadirnya bencana ini hendaklah disikapi secara lebih bijak. Penanganan gangguan mental dan kesehatan yang terjadi pasca bencana yang menuntut sinergi seluruh pihak yang langsung terkait, tidak lalu diartikan sebagai pembagian jatah dana yang telah terkumpul. Alih-alih ingin membantu meringankan beban penderitaan masyarakat yang terkena bencana, malah justru memicu bencana baru. Semoga tidak terjadi.

\section{Daftar. Pustaka}

Altrocchi; Ji.1980. Abnormal Behavior. New York: Harcourt Brace Jobanovich
Bloch, D. 2005. The Power of Social Support. http://www.davidposen.com/ pages/tips/tips20.html

Caplan, N., \& Nelson, S.D., 1973. On Being usepful: the nature and consequences of psychological research on social problems. American Psychologist, 28. 199-211.

China Broadcast. 2005. Trauma Psikologis Pasca Bencana Tsunami Perlu Diperhatikan, http:/l id.chinabroadcast.cn/1/2005/01/25/ 1023031.htm

Heller, K. \& Monahan, J. 1977. Psychology and community change. Homewood, Illinois: The Dorsey Press.

http://www. Jurnal-kopertis4.org/file/kopwil4283.doc. 2005. Mengkritisi peran televisi dalam wacana indonesia menangis

Ibrahim, A.S. 2005. Gempa, Tsunami, dan Stres. http://gis.bmg.go.id/ gempabumi aceh/berita46.asp. KCM, Senin, 03 Januari 2005, 04:08 WIB

http://www.pikiran-rakyat.com/cetak/2005/ 0105/09/hikmah/konsultasi.htm

Kaplan, R.M. Sallis., Jr.J.F. \& Patterson, Th. L. 1993. Health and human behavior. New York: McGraw-Hill Inc.

Korchin, S.J., 1976. Modem clinical psychology. New York: Basic Books.

Muhammad, M. 2005. Aceh, dari banjir air ke banjir uang. Bisnis Indonesia Senin, 10 Januari 2005. http:// 
www.transparansi.or.id/berita/beritajanuari2005/berita 100105.html

McDaniel, S.H. 1995. Collaborative between psychologist and family physicians: implementing the biopsychosocial model. Professional psychology: Research and Practice, Vol 26, 2: 117122.

Pastosuwido, S.R. 2000. Psikologi kesehatan: sumbangan psikologi dibidang kesehatan untuk prevensi dan intervensi. Peran Psikologi di. indonesaia. 1-21.
Pumomo, B, 2005. Penanggulangan Trauma Pasca-Tsunami. http:// www.suarakarya-online.com/ news.html?id=102369. Suara Karya Selasa, (01-02-'05)

Rappaport, H. 1977. Communitypsychology. New York: Holt, Rinehart and Winston.

Roan, W.M. 1984. Upaya Pencegahan dalam kesehatan jiwa, Cermin Dunia Kedokteran, No. 35: 10-17. 